
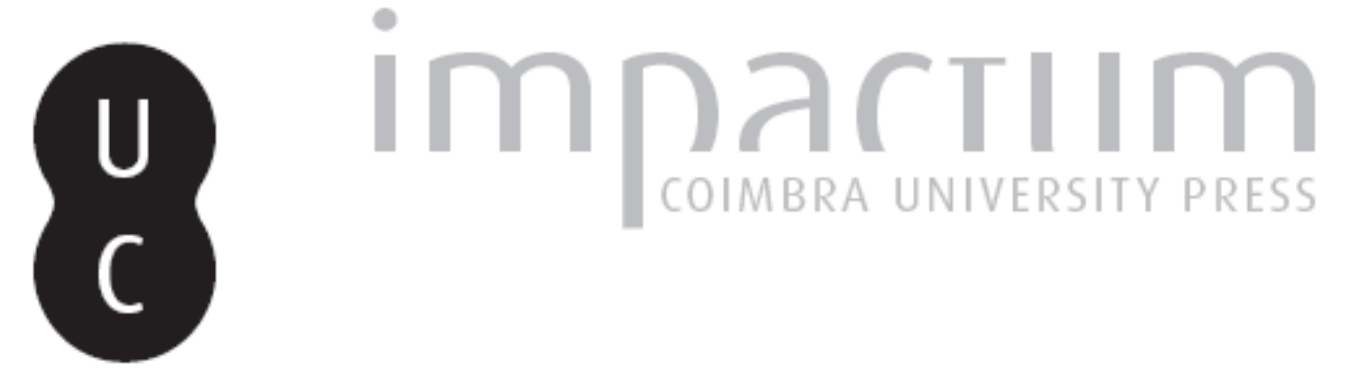

\title{
O projeto como síntese: a experiência do Atelier Integrado I - FAU/UFRJ
}

Autor(es): $\quad$ Fontes, Adriana Sansão; Slade, Ana

Publicado por: Editorial do Departamento de Arquitetura

URL persistente:

URI:http://hdl.handle.net/10316.2/37288

DOI:

DOI:http://dx.doi.org/10.14195/1647-8681_4_32

Accessed : $\quad$ 26-Apr-2023 11:22:54

A navegação consulta e descarregamento dos títulos inseridos nas Bibliotecas Digitais UC Digitalis, UC Pombalina e UC Impactum, pressupõem a aceitação plena e sem reservas dos Termos e Condições de Uso destas Bibliotecas Digitais, disponíveis em https://digitalis.uc.pt/pt-pt/termos.

Conforme exposto nos referidos Termos e Condições de Uso, o descarregamento de títulos de acesso restrito requer uma licença válida de autorização devendo o utilizador aceder ao(s) documento(s) a partir de um endereço de IP da instituição detentora da supramencionada licença.

Ao utilizador é apenas permitido o descarregamento para uso pessoal, pelo que o emprego do(s) título(s) descarregado(s) para outro fim, designadamente comercial, carece de autorização do respetivo autor ou editor da obra.

Na medida em que todas as obras da UC Digitalis se encontram protegidas pelo Código do Direito de Autor e Direitos Conexos e demais legislação aplicável, toda a cópia, parcial ou total, deste documento, nos casos em que é legalmente admitida, deverá conter ou fazer-se acompanhar por este aviso.

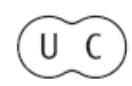




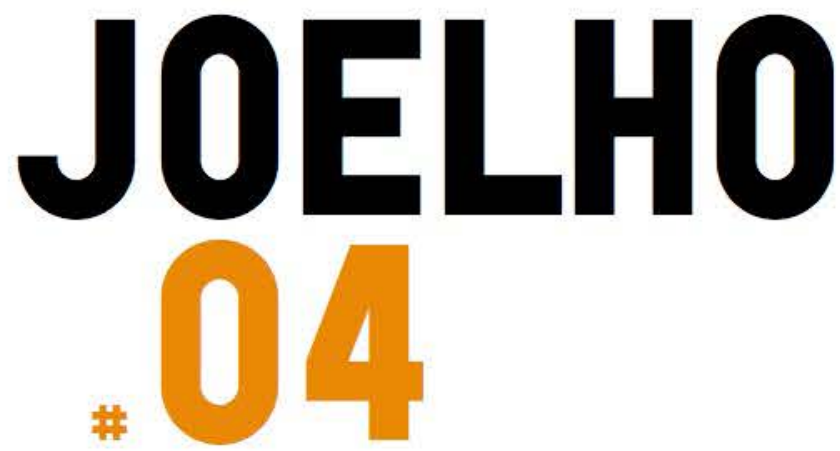

\section{ENSINAR PELO PROJETO \\ TEACHING THROUGH DESIGN}

\section{Coordenaçẫo:}

Paulo Providência

Gonçalo Canto Moniz

Alexandre Alves Costa Juan Domingo Santos Florian Beigel Philip Christou Elizabeth Hatz David Leatherbarrow Andrew Clancy Colm Moore Michael McGarry Willemijn Wilms Floet

Exposição TAPE 20Ir-12 


\section{Adriana Sansão Fontes Ana Slade \\ O projeto como síntese. A experiência do Âtelier

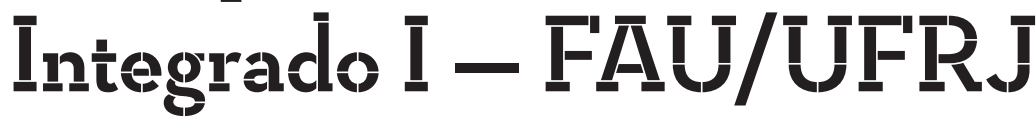

\section{Introdução}

O objetivo deste trabalho é apresentar a experiência, e reflexão crítica, acerca do Atelier Integrado da Faculdade de Arquitetura e Urbanismo da Universidade Federal do Rio de Janeiro (FAU/UFRJ), e sua importância como momento de síntese do conhecimento adquirido durante o curso de graduação dessa instituição.

Implantado na reforma curricular de 2005, o Atelier Integrado é uma disciplina que acontece em dois momentos do curso de graduação, que tem duração de cinco anos. O primeiro momento (AI-1) acontece no final do ciclo de fundamentação (4․ Período, $2^{\circ}$. ano), e o segundo momento (AI-2) encerra o ciclo de aprofundamento (80. período), preparando o aluno para os desafios do Trabalho Final de Graduação. Nosso interesse aqui é discutir este primeiro momento, o Atelier Integrado 1, analisando sua estrutura e objetivos, e propondo encaminhamentos para sua real integração.

O AI-1 é um atelier de projeto que reúne seis disciplinas: Projeto de Arquitetura, Projeto Paisagístico, Gráfica Digital, Concepção Estrutural, Processos Construtivos e Saneamento Predial, que estabelecem interfaces e sobreposições ao longo do semestre, a fim de integrar os aportes oriundos de diferentes áreas de conhecimento, tendo o projeto como fio condutor, e implicando considerável complexidade nos pontos de vista escalar, pragmático, compositivo e técnico.

O Atelier Integrado é uma antiga aspiração das escolas de arquitetura, porém de difícil execução, em grande parte devido à organização departamental estanque, a ao currículo da maioria das escolas de arquitetura brasileiras, onde "a disciplina de prática de projetos é apenas mais uma, competindo com as demais pelo tempo e a atenção dos estudantes" (Mahfuz, 2009), agravado ainda pela falta de coordenação entre os conteúdos de todas as disciplinas, tratadas como campos autônomos do conhecimento.

Procuraremos apontar as principais características da experiência do AI-1 na nossa escola, de forma a permitir uma crítica sobre os alcances e futuros desdobramentos, visando à melhoria do ensino de projeto e, consequentemente, a qualificação dos futuros arquitetos.

\section{Arquitetura + cidade}

Uma postura que demarca a visão ampliada do projeto arquitetônico é a opção por integrar Projeto de Arquitetura com Projeto Paisagístico, através da execução do edifício e do espaço público em uma disciplina conjunta. (fig.l)

Partimos da premissa de que arquitetura e cidade são indissociáveis, como já propunha Nolli, quando, em seu mapa de Roma, não estabelecia limites entre arquitetura e urbanismo. Uma falha por nós observada, em casos da história recente do ensino de projeto, tem sido o trato da arquitetura e urbanismo como disciplinas com limites rígidos, falha que rebate na cidade, onde o espaço público é constantemente relegado a um segundo plano, privilegiando o objeto arquitetônico. A associação entre as duas disciplinas significa a existência de um olhar específico sobre os espaços públicos, garantindo que eles serão, ao menos, considerados. (fig.2)

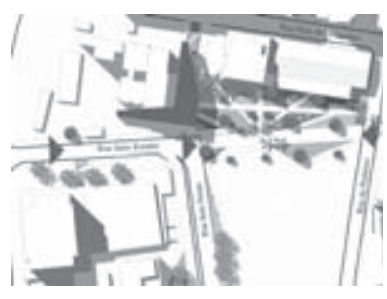

1. Edifício e espaço público projetados de forma integrada. Projeto de aluno (M. F. Fernandez, 2012-1).

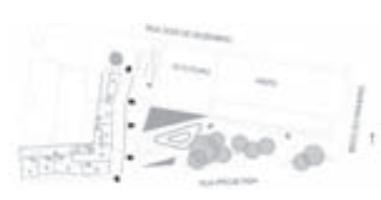

2. Edifício e espaço público projetados de forma integrada. Projeto de aluno (R. Ludiosa, 2012-1). 
Trata-se da visão sistêmica do projeto - defendida por Hertzberger (1999) - colocada em prática, onde consideramos a qualidade do espaço das ruas e dos edifícios como complementares - o domínio público - relacionando-os uns aos outros em um processo de potenciação mútua.

Com isso, trabalhamos com complexidades projetuais desde o ponto de vista escalar (através do domínio das diferentes escalas urbanas), programático (associando espaços livres e edificados relacionados a usos e atividades), e compositivo (entendendo o espaço livre também como elemento compositivo). ${ }^{1}$

Ressaltamos a importância da escolha do problema a ser tratado, o que significa relacionar o tema de trabalho a um contexto específico, de caráter didático. Nesse sentido, áreas consolidadas da cidade conferem maior complexidade ao projeto do que áreas dispersas, conduzindo os exercícios de projeto aos contextos urbanos densos. (fig.3)

Já diria Tschumi (2005, p.80) que "as condições complexas do sítio e do programa exigem que o contexto e o conteúdo sejam entendidos e atendidos. Como o contexto não pode ser ignorado ou eludido, deve conceituar-se", transformando suas idiossincrasias e restrições particulares na força que motiva o desenvolvimento de uma ideia arquitetônica ou conceito. (fig.4)

\section{O todo e as partes}

(...) as escolas de arquitetura são responsáveis pela consumação da separação de saberes e técnicas que confluem na atividade de projeto: não se pode entender - por mais que se esforcem em justificá-lo porque o desenho, a construção, a estabilidade e a climatização, para falar apenas do é que mais evidente, são consideradas disciplinas autônomas que são ministradas como matérias complementares ao projeto, não como técnicas sem as quais não há concepção possivel, por quanto são, ao mesmo tempo, condições e estímulo da mesma. (Piñon, 2007)

A integração das disciplinas de projeto com os conteúdos técnicos e teóricos significa, para os alunos, colocar em prática a totalidade do que é aprendido, de forma simultânea, colaborando para a síntese desde a fase inicial de projeto. (fig.5)

Todas as disciplinas funcionando de modo coordenado e direcionado ao ateliê cumpre uma dupla função: melhor assimilação dos conteúdos, uma vez que são simultaneamente praticados no ateliê, ou aplicados nos projetos, e compreensão, por parte dos estudantes, da ampla dimensão do projeto de arquitetura como síntese, que lida com questões técnicas e teóricas de múltiplas disciplinas. (fig.6)

Associado a esse ganho conceitual e metodológico, o fato de estarem os especialistas de diversas áreas, do projeto à construção, trabalhando juntos, e contribuindo, cada um na sua área, retira do professor de projeto a carga de "detentor da verdade", instrumentalizando os alunos para a síntese das informações na arquitetura em desenvolvimento.

Desenha-se, portanto, uma complexidade também no ponto de vista técnico, permitindo a exploração de diversos sistemas estruturais e construtivos, além do planejamento simultâneo da infraestrutura predial, não somente nas etapas executivas, mas durante todo o processo projetual.

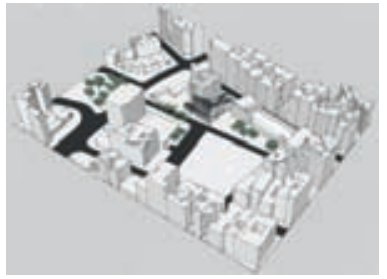

3. Edifício inserido em contexto urbano denso. Projeto de aluno (R. Ludiosa, 2012-1).
O dia a dia do atelier e a integração das disciplinas

As aulas expositivas de cada disciplina que compõe o AI-1 acontecem em horários independentes, e os conteúdos abordados são dirigidos à aplicação no projeto em desenvolvimento no atelier. Há um horário semanal compartilhado por todos os professores, quando encontram com os alunos no atelier para análise, crítica e discussão conjunta dos projetos em andamento. As atividades de atelier vão se intensificando com o andamento do semestre, enquanto a carga horária de aulas expositivas vai diminuindo.

O método de trabalho parte da análise e reflexão do contexto urbano, e da análise de projetos exemplares (fig.7) implantados em contextos densos, e/ou que apresentem o mesmo programa que está sendo trabalhado.

Consideramos de fundamental importância o diálogo com os projetos de referência desde a etapa preliminar do processo de concepção, conforme descrito por Lassance (2003) sobre o processo de concepção arquitetônica:

A pesquisa sobre os processos de concepção na arquitetura fornecem uma representação do projeto não como processo determinista de resolução de problemas, mas como uma atividade que pode ser descrita como um 'diálogo' (conversa) entre uma situação (espaço de condicionantes específicas) e o imaginário de referências do arquiteto. É através desse diálogo com a situação que o arquiteto constrói uma representação inicial do 'problema que ele resolve tratar'. (Lassance, 2003, p.9)

O autor acredita que o aluno não possui um espaço referencial construído a partir da experiência, sobretudo no ciclo de fundamentação. Logo, para "evitar que o estudante se deixe dominar somente pelas condicionantes contextuais" e pela "mítica 'folha branca", esse diálogo precisa ser resgatado, devendo ser fornecidos meios para problematizar sua prática projetual, principalmente através do debate e da pesquisa nas etapas iniciais da concepção, para que se possa definir uma "postura" pessoal diante de uma proposta.

Logo, as obras de referência, e toda a discussão e construção de uma teoria ou "leitura crítica" acerca dessas obras, "terão fundamental importância na orientação de um discurso retórico" e fornecerão um "ponto de partida ao processo de exploração projetual". (Lassance, 2003, p.7)

Para isso, são realizados seminários de análise e discussão de alguns projetos exemplares, a partir de maquetes e análises gráficas feitas pelos alunos. As discussões se dão a partir de temas de projeto, como por exemplo: relação do edifício com o contexto urbano, estruturas formais e espaciais, técnicas construtivas e materialidade, tipologias de unidades habitacionais, etc.

Após a análise dos projetos e da visita ao terreno, são gerados os primeiros estudos de implantação em maquete (protótipos) e desenho. O partido arquitetônico é escolhido dentre as diversas possibilidades experimentadas, permitindo que se parta para o desenvolvimento do edifício através de estudos em escala maior. A partir dessa fase, o uso da maquete eletrônica complementa o processo de concepção.

Em três momentos, ao longo do semestre, acontecem as bancas de avaliação, que, compostas de professores de todas as áreas,

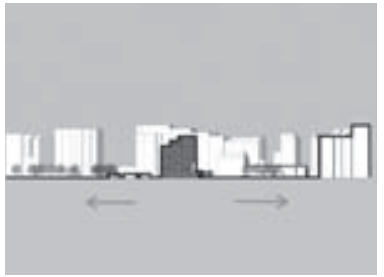

4. Edifício inserido em contexto urbano denso. Projeto de aluno (M. H. Santos, 2012-1). 
constituem mais uma oportunidade de encontro para a discussão e avaliação conjunta. Ao final do semestre, é montada uma exposição para divulgação dos resultados, quando painéis e maquetes são expostos nas circulações da faculdade.

\section{A transversalidade da representação}

Essa integração tem como eixo transversal a representação gráfica, tanto geométrica, quanto de expressão criativa. É através dela, na forma analógica ou digital, que as ideias ganham corpo e evoluem, porque podem ser vistas e corrigidas em um processo sucessivo e equilibrado: tanto o bom projeto, mal representado, quanto o mau projeto, bem representado, são resultados insuficientes para as expectativas do AI-1, já que a representação gráfica tem relação direta com a criação projetual. (fig.8)

Nesse sentido, estamos de acordo com Mahfuz (2009), quando afirma que "cabe ao ateliê a tarefa de mostrar como os aplicativos de modelagem podem ir além de sua condição de ferramenta sofisticada de desenho e revelar sua utilidade transcendental como ferramentas de projeto". A função da representação gráfica no atelier é a de participar no processo criativo, fazendo parte do circuito de comunicação autorautor e autor-interlocutor, e não a de mera disciplina de manipulação de softwares, ou mesmo de desenho livre. Evidentemente, evolui junto com o desenvolvimento do projeto, assumindo diferentes papéis ao longo do processo.

\section{Conclusões e avanços propostos: uma avaliação crítica}

Os Ateliers Integrados têm a pretensão de associar quatro grandes eixos de conhecimento: discussão, concepção, representação e construção. A formulação de duas disciplinas, em diferentes momentos, e responsáveis por colocar os quatro eixos em contato, gerou impactos positivos dentro da produção de escola, sentidos no dia a dia, mas também na produção "exportada" na forma de concursos de estudantes. (fig.9)

Os ganhos se devem à ampliação do entendimento do processo do projeto, em todas as etapas e partes que o constituem, e, portanto, do entendimento da arquitetura enquanto síntese. Paralelamente, se devem ao entendimento do projeto como sistema de relações entre espaço construído e livre.

Esses entendimentos, para o aluno, surgem da experiência de trabalhar em um processo global, que surge [1] da reflexão sobre o lugar, para [2] a proposição do partido arquitetônico e [3] criação da forma / espaço, [4] que será desenvolvida a partir de [5] um sistema estrutural e construtivo, [6] da escolha de materiais e [7] da solução da infraestrutura, culminando [8] no detalhamento construtivo em nível executivo.

No entanto, muitas deficiências ainda estão pendentes de solução, e criam empecilhos para uma integração de fato. A primeira delas é o próprio espaço físico da faculdade, caracterizado por salas cujo porte impede a realização de grandes ateliers com maior número de alunos e professores. Atualmente são constantes as reivindicações e ações para reverter esse quadro, o que também possibilitaria a realização de outro desejo do Atelier Integrado: que os alunos se apropriem dos ateliers

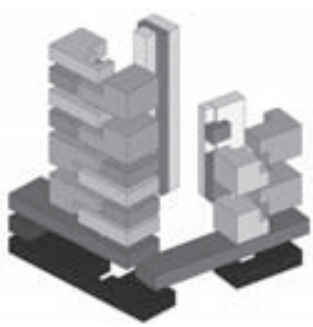

5. Diagrama conceitual da articulação das unidades residenciais com os demais elementos do edifício. Projeto de aluno (F. Carvalho, 2012-1).

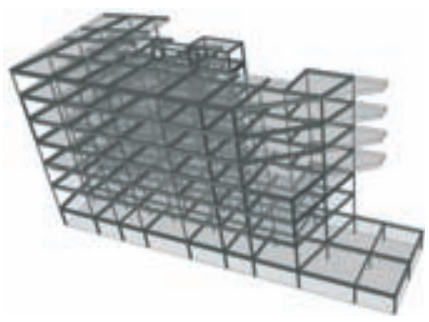

6. Concepção estrutural do edifício. Projeto de aluno (M. F. Fernandez, 2012-1).

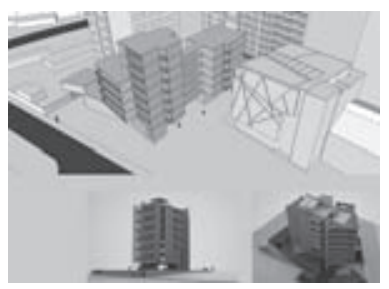

7. Aplicação da referência projetual (Edifício en Cassarate, arquiteto Angelo Bucci) no projeto do aluno (R. Assumpção, 2012-1).

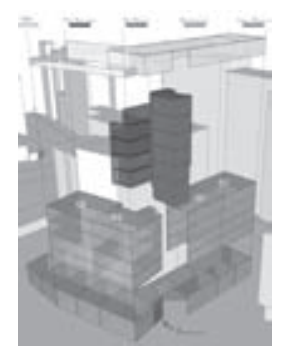

8. Diagrama representativo de todas as funções do edifício. Projeto de aluno (I. Silva, 2012-1).

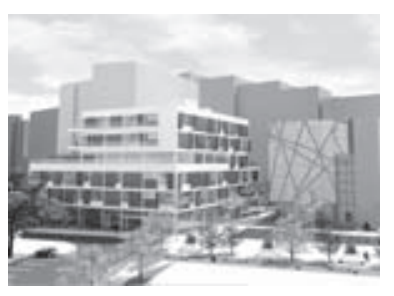

9. Perspectiva geral do projeto de aluno (M. F. Fernandez, 2012-1). 
também fora do horário das aulas, através dos "ateliers-livres", onde podem trabalhar coletivamente, assessorados por alunos-monitores.

O segundo empecilho é a ausência das disciplinas do eixo da discussão (teoria e história) dentro do atelier. Entendemos que a discussão teórica precisa ser ainda ampliada, e que os professores de teoria e história e de projeto poderiam trabalhar em conjunto na formação de um senso crítico, tanto em relação aos projetos de referência estudados, quanto em relação ao processo de concepção.

Quando falo em tratar de teoria no ateliê é preciso distinguir entre aquilo que normalmente é feito nas aulas de teoria da arquitetura - isto é, a apresentação e discussão das teorias conhecidas - da verdadeira teoria, que consiste na reflexão sobre a prática. A teoria nem precede nem se constitui em alternativa para a prática do projeto: o seu propósito deve ser sempre explicar os fatos que resistem à abordagem do mero sentido comum e contribuir para a "intensificação do entendimento visual, condição necessária da capacidade de julgar e, portanto, de conceber". (Piñon, 1999 apud. Mahfuz, 2009)

(...) A história entra no ateliê como veículo da construção de repertório. Seu foco aqui é restrito e diretamente relacionado aos temas projetuais em questão: analisa-se projetos exemplares em busca de informação sobre estruturas formais, relações com o entorno, técnicas construtivas, etc. Ao mesmo tempo, muitas vezes é imperativo explicitar as características e relevância da arquitetura do entorno em que se atua. (Mahfuz, 2009)

Associado ao segundo, o terceiro ponto são as disciplinas que ainda se desenvolvem de maneira dissociada, apesar de fazerem parte do conjunto do AI-1, o que demanda revisões e alinhamentos de conteúdos. Para tratar dessa questão, foi criada uma segunda coordenação no AI-1, responsável por promover reuniões entre os professores das diversas disciplinas para discussão dos conteúdos e preparação de um plano de aulas comum. A alta rotatividade docente também foi diagnosticada como um obstáculo para esse desejado alinhamento: seria interessante a manutenção de uma equipe fixa de professores por períodos mais longos.

Como quarto empecilho, julgamos que a presença das disciplinas de estrutura e processos construtivos no atelier deveria ser intensificada em momentos chave do processo, participando também da análise e discussão dos projetos de referência, de modo a subsidiar o aluno na compreensão dos sistemas estruturais e construtivos como parte integrante da definição do partido arquitetônico.

Finalmente, e não menos importante, se faz necessário o aumento da carga horária do Atelier Integrado, reforçando a importância do momento de integração e troca de ideias, como estratégia fundamental para a geração da boa arquitetura.

\footnotetext{
$1 \rightarrow$ Caderno da disciplina, redigido por diversos professores que já contribuíram em diferentes momentos de sua existência.
}

Referências bibliográficas

Hertzberger, H. (1999). Lições de Arquitetura. São Paulo: Martins Fontes.

-

Lassance, G. (2003). Ensinando a problematizar o projeto ou como lidar com a 'caixa preta' da concepção arquitetônica. In Anais Seminário Projetar, 2003. Natal: PPGAU/UFRN, $14 \mathrm{p}$.
Mahfuz, E. C. (2009). O atelier de projeto como mini-escola. Revista Vitruvius Arquitextos, 115, ano 10. Disponivel em http://www.vitruvius.com.br/ revistas/read/arquitextos/10.115/1.

Piñon, H. (2007). Reflexão sobre o ensino de arquitetura. Revista Vitruvius Arquitextos, 089, ano 08. Disponível em http://agitprop.vitruvius.com.br/ revistas/read/arquitextos/08.089/195/pt.
Piñon, H. (1999). Miradas Intensivas. Barcelona: Edicions UPC.

-

Tschumi, B. (2005). Concepto, contexto, contenido. Arquine, Revista Internacional de Arquitectura y Diseño, vol. 34. 